\title{
Effect of end-stage renal disease on long- term survival after a first-ever mechanical ventilation: a population-based study
}

\author{
Chin-Ming Chen ${ }^{1,3,4^{*}}$, Chih-Cheng Lai ${ }^{7}$, Kuo-Chen Cheng ${ }^{5,8}$, Shih-Feng Weng ${ }^{2,6}$, Wei-Lun Liu ${ }^{4,7}$
} and Hsiu-Nien Shen ${ }^{4,9^{*}}$

\begin{abstract}
Introduction: Patients with end-stage renal disease $\left(E S R D^{\text {Pos }}\right.$ ) usually have multiple comorbidities and are predisposed to acute organ failure and in-hospital mortality. We assessed the effect of ESRD on the poorly understood long-term mortality risk after a first-ever mechanical ventilation (1-MV) for acute respiratory failure.

Methods: The data source was Taiwan's National Health Insurance (NHI) Research Database. All patients given a 1-MV between 1999 and 2008 from one million randomly selected NHI beneficiaries were identified $(n=38,659)$. Patients with or without ESRD (ESRD ${ }^{\mathrm{Neg}}$ ) after a 1-MV between 1999 and 2008 were retrospectively compared and followed from the index admission date to death or the end of 2011. ESRD ${ }^{\text {Pos }}$ patients ( $n=1185$; mean age: 65.9 years; men: $51.5 \%$ ) were individually matched to ESRD ${ }^{\text {Neg }}$ patients (ratio: 1:8) using a propensity score method. The primary outcome was death after a 1-MV. The effect of ESRD on the risk of death after MV was assessed. A Cox proportional hazard regression model was used to assess how ESRD affected the mortality risk after a 1-MV.

Results: The baseline characteristics of the two cohorts were balanced, but the incidence of mortality was higher in ESRD $^{\text {Pos }}$ patients than in ESRD ${ }^{\text {Neg }}$ patients (342.30 versus 179.67 per 1000 person-years; $P<0.001$; covariate-adjusted hazard ratio: 1.43; $95 \%$ confidence interval: 1.31-1.51). For patients who survived until discharge, ESRD was not associated with long-term ( $>4$ years) mortality.
\end{abstract}

Conclusions: ESRD increased the mortality risk after a 1-MV, but long-term survival seemed similar.

\section{Introduction}

End-stage renal disease (ESRD) is becoming more common worldwide, especially in Taiwan. Since 2000, the incidence and prevalence of ESRD have increased [1]. According to the United States Renal Data System, Taiwan had the highest incidence (418 per million population) and prevalence (2226 cases per million population) of patients on chronic dialysis between 2000 and 2007 [2]. From 2006 to 2010, the number of patients on chronic dialysis increased from 52,081 to $65,883(+26.5 \%)$ [3, 4]. Because of their frequent multiple comorbidities, patients

\footnotetext{
* Correspondence: chencm3383@yahoo.com.tw; hsiunian@gmail.com 'Department of Recreation and Health-Care Management, Chia Nan University of Pharmacy and Science, No.60, Sec. 1, Erren Road., Rende District, Tainan 71710, Taiwan

${ }^{4}$ Department of Intensive Care Medicine, Chi Mei Medical Center, 901 Chung Hwa Road, Yungkang District, Tainan 710, Taiwan

Full list of author information is available at the end of the article
}

with ESRD (ESRD ${ }^{\text {Pos }}$ ) are prone to developing acute critical illnesses and have a higher mortality than do those without ESRD (ESRD ${ }^{\mathrm{Neg}}$ ) [5-11]. However, whether ESRD per se increases the risk of short-term and long-term mortality after critical illnesses remains controversial $[12,13]$. For example, several small cohort studies report that critically ill patients with ESRD have a higher risk of shortterm mortality than do those without ESRD $[8,14,15]$, and preexisting chronic kidney disease (CKD) indeed has a marked effect on the development of acute renal failure, 30-day, and 1-year mortality in critically ill patients who require mechanical ventilation (MV) [16]. Others, however, have found different results [7, 13]. One large cohort study showed that critically ill ESRD ${ }^{\text {Pos }}$ patients had a similar 1-year mortality rate to those without kidney dysfunction after age, illness severity, and admission type had been adjusted for [13]. Presumably, the observed difference in mortality in other studies is largely because of

C Biomed Central

(c) 2015 Chen et al. Open Access This article is distributed under the terms of the Creative Commons Attribution 4.0 International License (http://creativecommons.org/licenses/by/4.0/), which permits unrestricted use, distribution, and reproduction in any medium, provided you give appropriate credit to the original author(s) and the source, provide a link to the Creative Commons license, and indicate if changes were made. The Creative Commons Public Domain Dedication waiver (http://creativecommons.org/publicdomain/zero/1.0/) applies to the data made available in this article, unless otherwise stated. 
differences in the burden of comorbidities and the severity of acute illnesses rather than because of $\operatorname{ESRD}[7,13]$. Given these conflicting results, additional research on longer-term outcomes of these patients is needed.

MV is a life-support measure for patients with acute respiratory failure (ARF), who have a high rate of inhospital mortality (up to $35 \%$ ) [17]. When ESRD ${ }^{\text {Pos }}$ patients undergo $\mathrm{MV}$, there is a high rate of weaning failure and mortality $[18,19]$. Moreover, when MV is prolonged, the outcomes for these patients become even worse, with 1-year mortality as high as $60 \%$ [20]. However, whether ESRD predicts a worse long-term outcome in patients who undergo MV is not known.

Studies on critically ill ESRD ${ }^{\text {Pos }}$ patients focus primarily on those admitted to the intensive care unit (ICU) $[6,11]$. However, not all patients with critical illnesses are admitted to the ICU [21, 22]. Therefore, these studies usually have a selection bias. Moreover, ordering an invasive $\mathrm{MV}$ is usually a major critical decision for life-support measures in ESRD ${ }^{\text {Pos }}$ patients, whether or not they are admitted to the ICU. Information on the effects of ESRD on patients who undergo MV, instead of those admitted to the ICU, would be more relevant for patients. Therefore, we investigated the long-term outcomes of ESRD ${ }^{\text {Pos }}$ patients who underwent their first-ever MV (1-MV).

\section{Methods}

\section{Data source}

The data used in this study are from the National Health Insurance Research Database (NHIRD) established by Taiwan's National Health Research Institute (NHRI) to improve medical research. Taiwan's NHI program, instituted in March 1995, provides coverage for more than $99 \%$ of the country's legal residents; therefore, the NHIRD offers detailed healthcare services information on clinical visits for each insured beneficiary, using International Classification of Diseases, Ninth Revision, Clinical Modification (ICD-9-CM) diagnostic and procedure codes [23]. In the present study, data used came from the Longitudinal Health Insurance Database 2000 (LHID2000) [24], a sub-dataset of the NHI program, which contains all claims data, from 1996 to 2011, of one million NHI beneficiaries (about $4.34 \%$ of the total population) who were randomly selected from the year 2000 Registry of Beneficiaries of the NHIRD. There are no significant differences in gender distribution between beneficiaries in the LHID2000 and the NHIRD. The study was done according to the Declaration of Helsinki and was approved by the Institutional Review Board (IRB) at Chi Mei Medical Center (10308-E01). The IRB waived the need for informed consent from the enrolled participants because the data used in this study consists of nationwide, de-identified, secondary data released to the public for research purposes. This waiver does not adversely affect the rights and welfare of the enrollees.

\section{Patient selection and definition}

We enrolled all inpatients with a 1-MV for ARF during their first hospitalization between 1999 and 2008 $(n=38,659)$. ESRD ${ }^{\text {Pos }}$ patients (ICD-9-CM code 585) were detected using the NHI's catastrophic illness certification records, which included those who had undergone regular dialysis for at least 3 months. Those who were diagnosed with ESRD after a 1-MV were excluded $(n=1,013)$. The enrolled ESRD ${ }^{\text {Pos }}$ patients $(n=1,331)$ were then, using propensity score matching and the greedy matching algorithm (without replacement), individually matched to ESRD ${ }^{\mathrm{Neg}}$ controls in a $1: 8$ ratio. The propensity score, i.e., the probability of being ESRD $^{\text {Pos }}$, was estimated using a logistic regression model conditional on the covariates age, sex, length of ICU stay, length of hospital stay, duration of MV, department to which admitted, number of organ failures (other than respiratory and renal systems) [25], and individual comorbidities: diabetes mellitus (DM), hypertension (HTN), coronary artery disease (CAD), cirrhosis, chronic obstructive pulmonary disease (COPD), cancer, stroke, and congestive heart failure (CHF) (Additional file 1). Propensity score matching was used to reduce selection bias because it can bundle many confounding covariates that might be present in an observational study with this number of variables. The characteristics of the two groups were balanced after the propensity score matching (Table 1 ).

\section{Endpoint}

The primary endpoint (outcome) of the study was death after MV. Patients were followed from the index admission date to death or to the end of 2011. The secondary endpoint was to identify the risk factors for all-cause mortality after a 1-MV. We hypothesized that mortality is higher in $\operatorname{ESRD}^{\text {Pos }}$ patients than in ESRD ${ }^{\mathrm{Neg}}$ patients who require MV. The demographic and clinical characteristics of age; sex; length of hospital stay, length of ICU stay, and duration of MV; department to which admitted; number of organ failures; and comorbidities were used to estimate the mortality risk.

\section{Statistical analysis}

Differences in baseline characteristics between groups were evaluated using Pearson's $x^{2}$ test for categorical variables and Student's $t$ test for continuous variables. The incidence rate (IR) of death was calculated as cases per person-year. The overall and subgroup-specific relative mortality risks between the two groups were estimated using the incidence rate ratio (IRR) with a $95 \%$ confidence interval (CI) using the Poisson assumption. 
Table 1 Baseline characteristics of the study participants before and after propensity score matching

\begin{tabular}{|c|c|c|c|c|c|c|}
\hline \multirow[b]{2}{*}{ Variables } & \multicolumn{3}{|c|}{ Before propensity score matching } & \multicolumn{3}{|c|}{ After propensity score matching } \\
\hline & ESRD ${ }^{\text {Pos }}$ & ESRD $^{\text {Neg }}$ & $P$ & ESRD ${ }^{\text {Pos }}$ & ESRD ${ }^{\mathrm{Neg}}$ & $P$ \\
\hline Total & $1331(3.54)$ & $36,315(96.46)$ & & $1185(11.11)$ & $9480(88.89)$ & \\
\hline Age, years (mean $\pm S D$ ) & $65.02 \pm 12.97$ & $62.84 \pm 20.65$ & $<0.0001$ & $65.90 \pm 13.47$ & $65.48 \pm 14.99$ & 0.3005 \\
\hline Age group, years & & & $<0.0001$ & & & 0.8569 \\
\hline$<50$ & 159 (11.95) & $8454(23.28)$ & & $152(12.83)$ & $1264(13.33)$ & \\
\hline $50-64$ & $422(31.71)$ & 7079 (19.49) & & $339(28.61)$ & $2731(28.81)$ & \\
\hline$\geqq 65$ & $750(56.35)$ & $20,782(57.23)$ & & $694(58.57)$ & $5485(57.86)$ & \\
\hline Sex & & & $<0.0001$ & & & 0.2491 \\
\hline Female & $689(51.77)$ & $13,407(36.92)$ & & $575(48.52)$ & $4432(46.75)$ & \\
\hline Male & $642(48.23)$ & $22,908(63.08)$ & & $610(51.48)$ & $5048(53.25)$ & \\
\hline \multicolumn{7}{|l|}{ Comorbidity } \\
\hline Diabetes & $703(52.82)$ & $9779(26.93)$ & $<0.0001$ & $568(47.93)$ & $4379(46.19)$ & 0.2573 \\
\hline Hypertension & $903(67.84)$ & $15,755(43.38)$ & $<0.0001$ & 757 (63.88) & $5954(62.81)$ & 0.4697 \\
\hline CAD & $458(34.41)$ & $8173(22.51)$ & $<0.0001$ & $377(31.81)$ & $2948(31.10)$ & 0.6153 \\
\hline Liver cirrhosis & $137(10.29)$ & $2954(8.13)$ & 0.0048 & $120(10.13)$ & $1025(10.81)$ & 0.4722 \\
\hline COPD & $175(13.15)$ & $8715(24.00)$ & $<0.0001$ & $175(14.77)$ & $1394(14.70)$ & 0.9538 \\
\hline Cancer & $184(13.82)$ & $7912(21.79)$ & $<0.0001$ & $183(15.44)$ & $1475(15.56)$ & 0.9172 \\
\hline Stroke & $368(27.65)$ & $9952(27.40)$ & 0.8448 & $343(28.95)$ & $2711(28.60)$ & 0.8027 \\
\hline $\mathrm{CHF}$ & $279(20.96)$ & $5024(13.83)$ & $<0.0001$ & $215(18.14)$ & $1699(17.92)$ & 0.8514 \\
\hline Department to which admitted & & & $<0.0001$ & & & 0.6634 \\
\hline Surgery & $325(24.42)$ & $14,358(39.54)$ & & $324(27.34)$ & $2649(27.94)$ & \\
\hline Medical & $1006(75.58)$ & $21,957(60.46)$ & & $861(72.66)$ & $6831(72.06)$ & \\
\hline $\begin{array}{l}\text { Number of organ failures (other than } \\
\text { lungs and kidneys) }\end{array}$ & & & $<0.0001$ & & & 0.8884 \\
\hline 0 & $960(72.13)$ & $28,900(79.58)$ & & 867 (73.16) & $6979(73.62)$ & \\
\hline 1 & $346(26.00)$ & $6779(18.67)$ & & $294(24.81)$ & $2298(24.24)$ & \\
\hline$\geqq 2$ & $25(1.88)$ & $636(1.75)$ & & $24(2.03)$ & $203(2.14)$ & \\
\hline Ventilator duration (days) (continuous) & $11.69 \pm 25.34$ & $18.15 \pm 84.99$ & $<0.0001$ & $11.57 \pm 25.23$ & $11.93 \pm 29.57$ & 0.6494 \\
\hline ICU days, mean \pm SD & $10.25 \pm 16.48$ & $9.75 \pm 17.18$ & 0.2839 & $9.93 \pm 15.32$ & $10.07 \pm 17.18$ & 0.7883 \\
\hline Hospital days, mean \pm SD & $24.06 \pm 28.14$ & $25.28 \pm 54.04$ & 0.1391 & $23.92 \pm 28.21$ & $22.89 \pm 32.11$ & 0.2444 \\
\hline
\end{tabular}

Data are number (percentages) unless otherwise specified

ESRD end stage renal disease, ESRD Pos patients with ESRD, ESRD Neg patients without ESRD, CAD coronary artery disease, COPD chronic obstructive airway disease, CHF congestive heart disease, ICU intensive care unit

The actuarial survival rate of the two groups was determined using the Kaplan-Meier method, and a log-rank test was used to compare the difference between the two survival curves. The effect of ESRD on the mortality risk after MV was assessed using a Cox proportional hazards regression model. Covariates included in the Cox model were those used in the propensity score matching (mentioned in the "Patient selection and definition" subsection above). The proportional hazard assumption was verified using plots of natural log transformed (ln) (survival function) versus ln (time). The data are mean \pm standard deviation or number (percentages). Significance was set at $P<0.05$. SAS 9.3.1 for Windows (SAS Institute, Cary, NC, USA) was used for all analyses.

\section{Results}

The initial survey included 37,646 patients. After matching, 10,665 patients with a 1-MV (ESRD ${ }^{\text {Pos }}$ : 1185 and ESRD $^{\text {Neg. }}$ 9480) were selected. Before propensity score matching, the ESRD ${ }^{\text {Pos }}$ group contained more patients who were older, female, and had comorbid DM, HTN, CAD, cirrhosis, and $\mathrm{CHF}$, and contained fewer patients who had COPD and cancer, a higher prevalence of one or more organ failures, and fewer days on MV than did ESRD $^{\mathrm{Neg}}$ patients (Table 1). In addition, about $12.17 \%$ 
$(162 / 1331)$ of the ESRD ${ }^{\text {Pos }}$ patients and $9.76 \%$ (3545/ $36,315)$ of the ESRD ${ }^{\mathrm{Neg}}$ patients had undergone MV outside the ICU (data not shown). After propensity score matching, with the correction of all the above variables, 1185 (90.39\%) of the 1331 ESRD $^{\text {Pos }}$ patients were matched to 9480 ESRD $^{\mathrm{Neg}}$ controls (Table 1). The mortality rate of ESRD ${ }^{\mathrm{Pos}}$ patients was nearly twice as high as that of ESRD ${ }^{\mathrm{Neg}}$ patients (IRR = 1.92) (Table 2). The risk difference in mortality between the two groups was significant across all subgroups with the exception of those with liver cirrhosis, cancer, and multiple organ failure. The highest risk difference was for patients admitted to the Surgery Department $(I R R=2.95)$, and the lowest was for patients with CHF (IRR = 1.35). In followups within 4 years, ESRD ${ }^{\text {Pos }}$ patients had a higher mortality rate (IRR, 0-6 months: 1.59 ; 6-12 months: 1.84 ; 1-2 years: 1.65 and $2-4$ years: 1.69 ). After 4 years of follow-up, however, there was no significant difference in mortality rates between $\operatorname{ESRD}^{\mathrm{Pos}}$ and $\operatorname{ESRD}^{\mathrm{Neg}}$ patients. The 30-day, 6-month, and 1-, 2-, 5-, and 10-year survival rate differences in the ESRD ${ }^{\text {Pos }}$ and ESRD ${ }^{\text {Neg }}$ groups from the beginning are listed in Additional file 2.

Table 2 The overall and subgroup-specific incidence rates (IR) and incidence rate ratios (IRR) of death between ESRD ${ }^{\text {Pos }}$ patients and matched ESRD ${ }^{\text {Neg }}$ controls

\begin{tabular}{|c|c|c|c|c|c|c|c|c|}
\hline \multirow[t]{2}{*}{ Variables } & \multicolumn{3}{|c|}{ ESRD $^{\text {Pos }}$ patients } & \multicolumn{3}{|c|}{ ESRD $^{\text {Neg }}$ controls } & \multirow[t]{2}{*}{$\operatorname{IRR}(95 \% \mathrm{Cl})$} & \multirow[t]{2}{*}{$P$} \\
\hline & Total $(n)$ & Death $(n)$ & IR (per 1000 person-years) & Total $(n)$ & Death $(n)$ & IR (per 1000 person-years) & & \\
\hline All & 1185 & 898 & 342.30 & 9480 & 5806 & 179.67 & $1.92(1.79-2.07)$ & $<0.0001$ \\
\hline \multicolumn{9}{|l|}{ Age group, years } \\
\hline$<50$ & 152 & 90 & 175.34 & 1264 & 509 & 80.90 & $2.17(1.73-2.71)$ & $<0.0001$ \\
\hline $50-64$ & 339 & 241 & 261.52 & 2731 & 1481 & 142.16 & $1.84(1.61-2.11)$ & $<0.0001$ \\
\hline$\geqq 65$ & 694 & 567 & 477.04 & 5485 & 3816 & 244.53 & $1.95(1.79-2.13)$ & $<0.0001$ \\
\hline \multicolumn{9}{|l|}{ Sex } \\
\hline Male & 610 & 474 & 388.34 & 5048 & 3102 & 179.79 & $2.16(1.96-2.38)$ & $<0.0001$ \\
\hline Female & 575 & 424 & 302.25 & 4432 & 2704 & 179.64 & $1.68(1.52-1.86)$ & $<0.0001$ \\
\hline \multicolumn{9}{|l|}{ Comorbidity } \\
\hline Diabetes & 568 & 447 & 411.98 & 4379 & 2946 & 224.98 & $1.83(1.66-2.02)$ & $<0.0001$ \\
\hline Hypertension & 757 & 570 & 336.70 & 5954 & 3764 & 193.81 & $1.74(1.59-1.90)$ & $<0.0001$ \\
\hline$C A D$ & 377 & 293 & 386.34 & 2948 & 1830 & 181.80 & $2.13(1.88-2.40)$ & $<0.0001$ \\
\hline Liver cirrhosis & 120 & 101 & 481.91 & 1025 & 839 & 449.78 & $1.07(0.87-1.32)$ & 0.5123 \\
\hline COPD & 175 & 153 & 602.27 & 1394 & 960 & 219.92 & $2.74(2.31-3.25)$ & $<0.0001$ \\
\hline Cancer & 183 & 138 & 339.96 & 1475 & 1068 & 294.69 & $1.15(0.97-1.38)$ & 0.1142 \\
\hline Stroke & 343 & 278 & 463.19 & 2711 & 1852 & 236.90 & $1.96(1.72-2.22)$ & $<0.0001$ \\
\hline $\mathrm{CHF}$ & 215 & 161 & 338.72 & 1699 & 1179 & 251.31 & $1.35(1.14-1.59)$ & 0.0004 \\
\hline \multicolumn{9}{|c|}{ Department to which admitted } \\
\hline Surgery & 324 & 225 & 257.56 & 2649 & 1133 & 87.26 & $2.95(2.56-3.41)$ & $<0.0001$ \\
\hline Medical & 861 & 673 & 384.60 & 6831 & 4673 & 241.73 & $1.59(1.47-1.72)$ & $<0.0001$ \\
\hline \multicolumn{9}{|c|}{ Number of organ failures (other than lungs and kidneys) } \\
\hline 0 & 867 & 633 & 290.32 & 6979 & 3812 & 136.93 & $2.12(1.95-2.31)$ & $<0.0001$ \\
\hline 1 & 294 & 245 & 589.45 & 2298 & 1818 & 430.62 & $1.37(1.20-1.56)$ & $<0.0001$ \\
\hline$\geqq 2$ & 24 & 20 & 728.53 & 203 & 176 & 691.46 & $1.05(0.66-1.67)$ & 0.8249 \\
\hline \multicolumn{9}{|l|}{ Follow-up } \\
\hline $0-6$ month & 1185 & 717 & 2497.50 & 9480 & 4445 & 1571.80 & $1.59(1.47-1.72)$ & $<0.0001$ \\
\hline 6-12 months & 468 & 44 & 197.37 & 5035 & 263 & 107.515 & $1.84(1.33-2.53)$ & 0.0002 \\
\hline $1-2$ years & 424 & 46 & 115.34 & 4772 & 321 & 69.83 & $1.65(1.21-2.25)$ & 0.0015 \\
\hline $2-4$ years & 378 & 52 & 76.36 & 4451 & 374 & 45.28 & $1.69(1.26-2.25)$ & 0.0004 \\
\hline 4-6 years & 292 & 22 & 45.21 & 3616 & 186 & 30.25 & $1.49(0.96-2.32)$ & 0.0747 \\
\hline$>=6$ years & 196 & 17 & 31.08 & 2537 & 217 & 27.01 & $1.15(0.70-1.89)$ & 0.5570 \\
\hline
\end{tabular}

ESRD end stage renal disease, ESRD ${ }^{\text {Pos }}$ with ESRD, ESRD ${ }^{N e g}$ without ESRD, IRR incidence rate ratio, $C l$ confidence interval, IR incidence rate, $C A D$ coronary artery disease, COPD chronic obstructive airway disease, CHF congestive heart disease 
ESRD $^{\text {Pos }}$ patients after a 1-MV showed a precipitous decline in mortality early on, and a parallel course thereafter, which suggests that although the starting point is lower, the trajectory has not changed (Fig. 1). After 4 years, the survival curves seem to be almost parallel, which might indicate that ESRD increases short-term but not long-term mortality. Patients who were older, had more organ failures, and had been admitted to the Surgery Department had a significantly higher mortality (Fig. 2a-c), but there was no significant difference in the survival rate between males and females (Fig. 2d).

ESRD $^{\text {Pos }}$ patients had a lower survival rate than did ESRD $^{\mathrm{Neg}}$ patients (hazard ratio [HR] 1.43; $95 \% \mathrm{CI}$ : 1.33-1.54). In addition to ESRD, some important factors predicting mortality for patients after a $1-\mathrm{MV}$ included older age (50-64 years old: $H R=1.50 ; \geq 65$ years old: $\mathrm{HR}=2.03$ : compared with $0-50$ years old), being female $(\mathrm{HR}=0.94)$, admitted to a surgery department $(0.64)$, more organ failures (1: $H R=1.85 ; \geq 2$ : $H R=2.46$ : compared with 0$), \mathrm{DM}(\mathrm{HR}=1.18)$, liver cirrhosis $(\mathrm{HR}=1.61)$, cancer (1.49), stroke (1.26), and CHF (1.17) (Table 3). The HR of death in ESRD ${ }^{\text {Pos }}$ patients treated with MV is shown in Additional file 3.

\section{Discussion}

We found that after age, severity of illness, comorbidities, and department to which admitted had been adjusted for, ESRD after a 1-MV was associated with a higher risk for mortality $(H R=1.43)$, regardless of whether the patient had been admitted to the ICU. We also found that about $9.85 \%(3707 / 37,646)$ of ESRD ${ }^{\text {Pos }}$ 1-MV patients had never been admitted to the ICU (data not shown), which is consistent with other reports
$[21,22]$. The present study appears to be the first to describe long-term outcomes of ESRD ${ }^{\text {Pos }}$ patients with a 1-MV and to include patients not admitted to the ICU. Our findings are compatible with most other studies on ESRD $^{\text {Pos }}$ patients admitted to the ICU. One study of 276,731 adults admitted to the ICU reported that after the patients had been discharged from the ICU, inhospital mortality rates were much higher in ESRD ${ }^{\text {Pos }}$ patients than in ESRD $^{\mathrm{Neg}}$ patients $(45.3 \%$ versus $31.2 \%$; $P<0.001)$ [9].

Go et al. also showed that ESRD ${ }^{\text {Pos }}$ patients have a relative risk for all-cause mortality 5.9 times greater than do patients with healthy renal function [26]. Another study reported that ESRD ${ }^{\text {Pos }}$ patients had higher rates of ICU and in-hospital mortality than did matched pairs of patients (23.1\% versus $15.1 \%$, and $31.2 \%$ versus $19.1 \%$, $P<0.05)$ [10]. Other studies have reported that critically ill patients on chronic dialysis are estimated to have the following mortality rates: in-hospital: $14 \%$ to $56 \%$, 30day: $32 \%$ to $41 \%$, and 90 -day: $42 \%$ to $44.6 \%$ [6], and that longer-term mortality rates might be as high as 38 $\%$ (6 months) and $48 \%$ (12 months) [27]. There are few studies on the long-term outcomes of ESRD ${ }^{\text {Pos }}$ patients after a 1-MV, except for one on 47 patients, which reported an overall cumulative proportional in-hospital survival rate of only $17 \%$, a 1 -year rate of $40 \%$, and a 3-year rate of $25 \%$ [18]. Liao et al. also said that ESRD $^{\text {Pos }}$ patients had a significantly higher mortality rate than did ESRD ${ }^{\mathrm{Neg}}$ patients $(76.7 \%$ versus $28.8 \%$ ) 1 year after traumatic brain injury [28]. Those studies were exclusively on patients admitted to the ICU, however.

In contrast, others have found different results. A large population-based cohort study of nonspecific critically ill

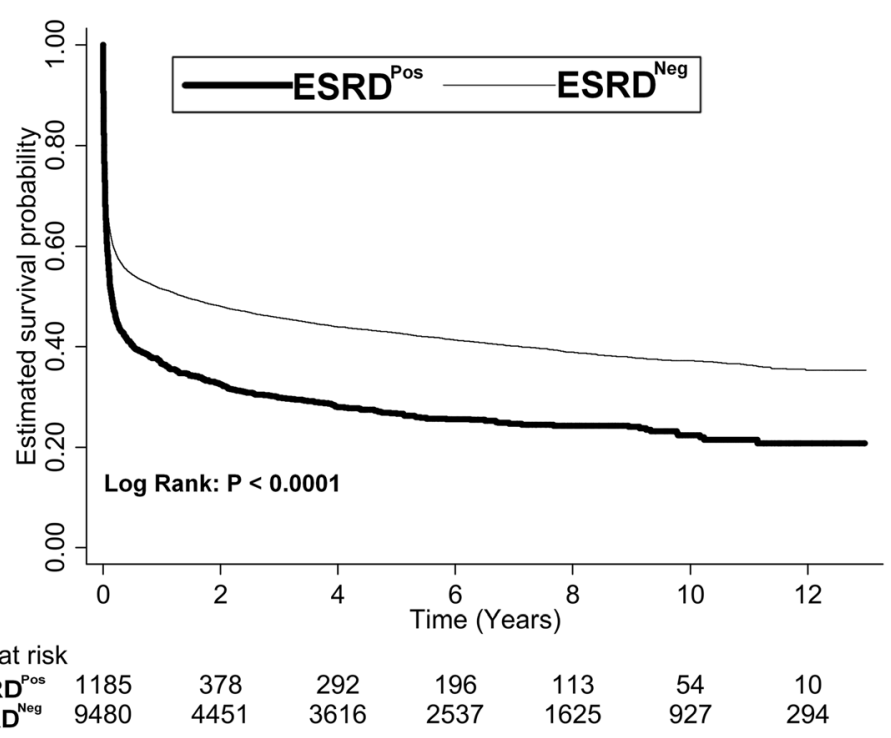

Fig. 1 Kaplan-Meier survival curves of ESRD ${ }^{\text {Pos }}$ patients and ESRD ${ }^{\mathrm{Neg}}$ controls. ESRD end stage renal disease 

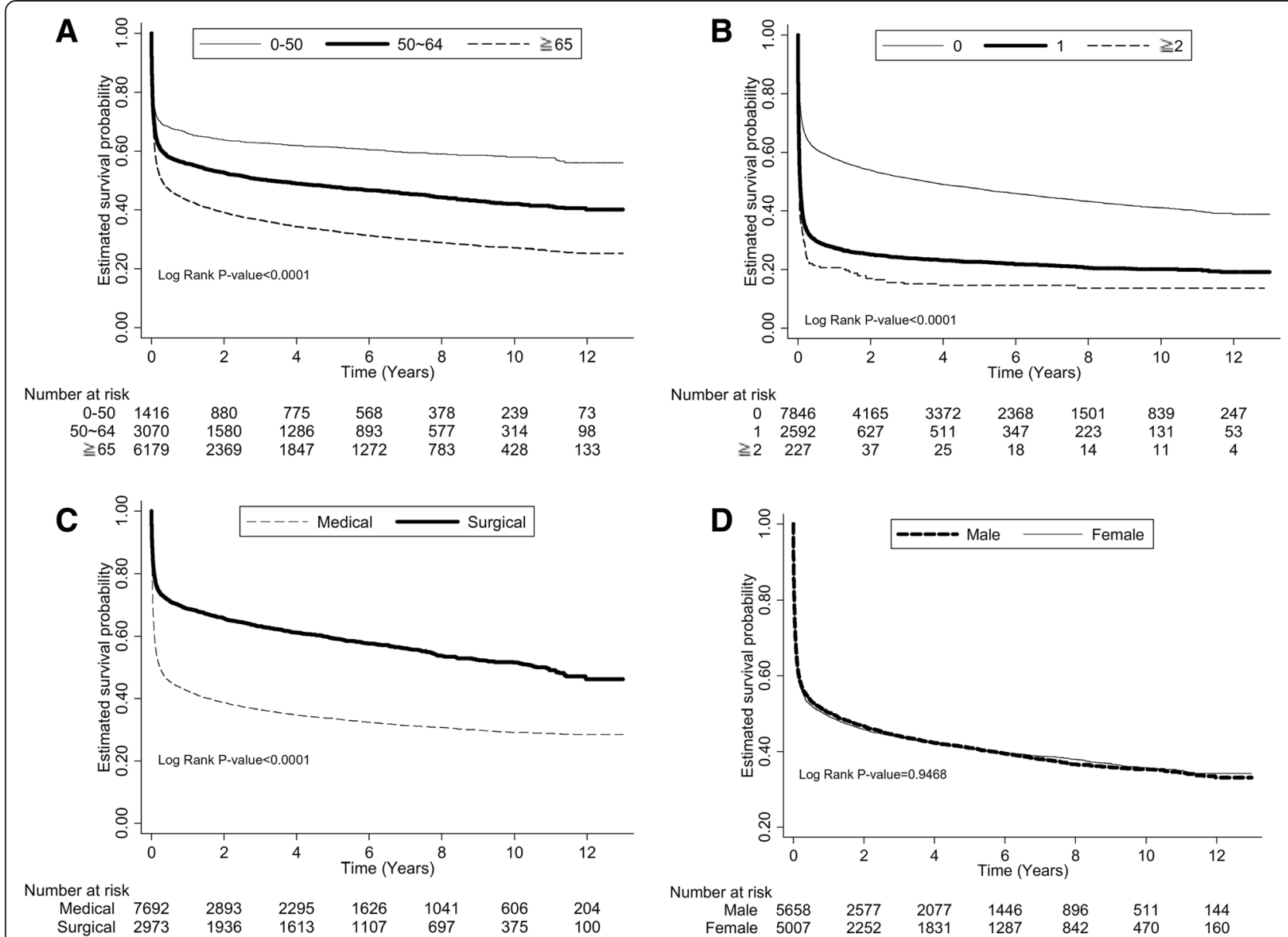

Fig. 2 Kaplan-Meier survival curves of different groups: (a) age; (b) number of organ failures; (c) departments to which patients were admitted; (d) sex

patients (5693 admissions) showed that any kidney dysfunction is associated with an increased risk for longterm death, with the exception of ESRD ${ }^{\text {Pos }}$ patients, who had outcomes similar to those of patients with no kidney dysfunction [13]. Strijack et al. [7] said that the unadjusted in-hospital mortality rate was higher for ESRD $^{\text {Pos }}$ patients (16\% versus $11 \%$ ), but that this difference did not persist after an adjustment for baseline illness severity, and that the higher mortality rate was due to comorbidity but not to ESRD itself. Moreover, Chapman et al. [29] reported that ESRD ${ }^{\text {Pos }}$ patients who were alive after they had been discharged from the ICU had a 2-year survival rate of $56 \%$, but that the long-term mortality rate between ESRD ${ }^{\text {Pos }}$ patients and matched ESRD ${ }^{\text {Neg }}$ controls was similar after excluding patients who had died within a month of being discharged from the ICU [29]. We thought that because of different inclusion criteria, critically ill ESRD ${ }^{\text {Pos }}$ patients might have different long-term outcomes because they have different comorbidities. Despite possible bias, including possible MV patients not admitted to the ICU, and matching using propensity scores, our study showed that ESRD ${ }^{\text {Pos }}$ patients with a 1MV had a higher IRR of death per 1000 person-years than did almost all the groups (stratified by age, sex, department admitted by, number of organ failures, and comorbidities) and a higher covariate-adjusted HR (1.43) than did ESRD ${ }^{\text {Neg }}$ controls. The long-term outcomes and the long-term mortality rates of those who survived for more than 4 years after they had been discharged from the hospital were similar between ESRD ${ }^{\text {Pos }}$ and ESRD ${ }^{\mathrm{Neg}}$ patients.

After a Cox proportional hazards analysis, we showed that the mortality predictors of our patients treated with MV included ESRD, older age, and being male, findings consistent with the literature. Other researchers have reported that ESRD predicted in-hospital or 30-day mortality in patients with ARF and MV admitted to the ICU in spite of aggressive treatment $[19,30]$, and that for patients with prolonged MV, ESRD also predicted 1-year mortality [20]. Moreover, many studies have reported the effect of age on the mortality of patients treated with MV [13, 20, 30-34]. For example, a retrospective study [34] of 61,113 patients treated with MV 
Table 3 Crude and adjusted hazard ratios (HR) of death in all ventilated patients (derived using Cox proportional hazard regression models)

\begin{tabular}{|c|c|c|}
\hline Cohort & $\begin{array}{l}\text { Crude HR } \\
(95 \% \mathrm{Cl})\end{array}$ & $\begin{array}{l}\text { Adjusted HR } \\
(95 \% \mathrm{Cl})\end{array}$ \\
\hline \multicolumn{3}{|l|}{ ESRD } \\
\hline Yes & $1.47(1.36-1.57)$ & $1.43(1.33-1.54)$ \\
\hline No & 1.00 & 1.00 \\
\hline \multicolumn{3}{|l|}{ Age (years) } \\
\hline $0-50$ & 1.00 & 1.00 \\
\hline $50-64$ & $1.51(1.37-1.66)$ & $1.50(1.36-1.65)$ \\
\hline$\geqq 65$ & $2.18(1.99-2.38)$ & $2.03(1.85-2.23)$ \\
\hline \multicolumn{3}{|l|}{ Sex } \\
\hline Female & $1.00(0.95-1.05)$ & $0.94(0.89-0.99)$ \\
\hline Male & 1.00 & 1.00 \\
\hline \multicolumn{3}{|l|}{ Comorbidity } \\
\hline Diabetes & $1.30(1.24-1.36)$ & $1.18(1.13-1.25)$ \\
\hline Hypertension & $1.10(1.05-1.16)$ & $0.99(0.94-1.05)$ \\
\hline Coronary artery disease & $1.00(0.95-1.06)$ & $0.93(0.88-1.01)$ \\
\hline Liver cirrhosis & $1.90(1.77-2.04)$ & $1.61(1.50-1.74)$ \\
\hline COPD & $1.20(1.12-1.28)$ & $1.01(0.95-1.08)$ \\
\hline Cancer & $1.33(1.24-1.41)$ & 1.49 (1.39-1.59) \\
\hline Stroke & $1.28(1.21-1.34)$ & $1.26(1.19-1.33)$ \\
\hline $\mathrm{CHF}$ & $1.24(1.17-1.32)$ & $1.17(1.10-1.25)$ \\
\hline
\end{tabular}

Department to which admitted

$\begin{array}{lll}\text { Surgery } & 0.50(0.47-0.53) & 0.64(0.60-0.68) \\ \text { Medical } & 1.00 & 1.00\end{array}$

Number of organ failures (other than lungs and kidneys)

$\begin{array}{lll}0 & 1.00 & 1.00 \\ 1 & 2.14(2.03-2.26) & 1.85(1.75-1.95) \\ \geq 2 & 2.79(2.41-3.23) & 2.46(2.12-2.86)\end{array}$

Ventilator duration (days) (continuous) $1.00(1.00-1.00) \quad 1.00$ (1.00-1.00) ICU stay (days) (continuous) $1.00(1.00-1.00) \quad 1.00(1.00-1.01)$ Hospital stay (days) (continuous)

$0.99(0.99-1.00) \quad 1.00(0.99-1.00)$

HR hazard ratio, $\mathrm{Cl}$ confidence interval, ESRD end-stage renal disease, COPD chronic obstructive airway disease, CHF congestive heart disease, ICU intensive care unit

showed that factors independently associated with an increased mortality rate included being $>80$ years old, and two recent studies also reported that older age was a consistent hazard [30, 32]. Esteban et al. [31], too, said that older age $(40-70$ years: $H R=1.60$ and $>70$ years: $\mathrm{HR}=2.11$, compared with $<40$ years) was associated with a higher ICU mortality rate in 5183 patients treated with $\mathrm{MV}$, which is in line with our finding.

In addition, the influence of sex on mortality rates in patients treated with MV is inconsistent. One study reported that women had a greater risk for in-hospital mortality [35], but another reported no such association [30]. In contrast, two large studies showed that being male predicted higher in-hospital mortality in patients treated with MV $[36,37]$. Our study showed no significant differences in survival between the sexes, but the difference was significant after bias had been adjusted for. Differences in inclusion criteria, race, populationbased cohorts, and geographic distribution make it difficult to generalize the effect of sex on critically ill patients.

Our study is also consistent with the literature, which shows that patients admitted to medical rather than surgical departments have more organ failures, and that comorbidities (e.g., DM, liver cirrhosis, cancer, stroke, and CHF) predicted worse outcomes. Manzano et al. found that a medical department admission was a significant predictor of mortality in patients requiring MV [38]. Other studies report that multiple organ failure is independently associated with mortality in patients with $\mathrm{MV}$ [30, 34, 39]. Similarly, the comorbidities of DM, CHF, stroke, liver cirrhosis, and cancer have been reported as independent predictors of short-term and long-term mortality in patients with MV [30, 32, 34, 38, 40, 41], which is consistent with our findings.

We also found that ESRD ${ }^{\text {Pos }}$ patients with MV were older, more often admitted to medical departments; and more often had comorbid DM, HTN, CAD, liver cirrhosis, and CHF than did ESRD ${ }^{\mathrm{Neg}}$ patients before matching, although these factors could also be mortality contributors after matching. This was consistent with other studies $[9,10,26]$. In general, patients on longterm dialysis admitted to the ICU tend to have higher illness severity scores and multiple comorbidities, and to need more medical resources than does the general population [1].

\section{Strengths and limitations}

Our study has some strengths. First, it is a large population-based analysis of the effect of ESRD on patients given a 1-MV, which includes patients not admitted to the ICU; this differentiates the present study from others. Second, the nationwide study design largely reduced the effect of referral bias, which is often seen in critical care studies.

Our study also has some limitations. First, all diagnoses, including comorbidities, relied on the claims data and ICD-9-CM diagnosis codes, which might lead to disease misclassification. Second, the NHIRD does not differentiate the stages of CKD in ESRD ${ }^{\mathrm{Neg}}$ patients. Third, we were unable to take into account the illness severity scores of ESRD ${ }^{\text {Pos }}$ patients with MV because the data were unavailable; thus, we included the number of organ failures as a proxy for severity. Fourth, as in all observational studies, our study might contain some 
residual confounding; thus, it cannot show causality but only association between risk factors and mortality. Fifth, we excluded 146 ESRD $^{\text {Pos }}$ patients (>10 \%) because we were unable to match them with ESRD ${ }^{\mathrm{Neg}}$ patients; this might contribute bias to our conclusions. Finally, not all patients were admitted to the ICU, which might have affected our evaluations of outcomes.

\section{Conclusions}

Regardless of whether a patient is admitted to the ICU, being ESRD ${ }^{\text {Pos }}$ significantly increases the risk of death within 4 years after a 1-MV. After 4 years, however, survival rates are not significantly different. In addition to ESRD, older age, being male, being admitted by a medical department, multiple organ failure, and a history of comorbidities (DM, liver cirrhosis, cancer, stroke, and CHF) are associated with a higher mortality rate after a 1-MV. Physicians should keep these high-risk groups in mind and explain the prognosis to patients' families when treating critical patients undergoing a 1-MV.

\section{Key messages}

- ESRD-positive patients who underwent their first-ever mechanical ventilation were older, more often female, admitted to a medical department, had comorbid diabetes mellitus, hypertension, coronary artery disease, liver cirrhosis, and congestive heart failure than did ESRD-negative control patients before propensity score matching.

- After matching, the mortality rate of ESRD-positive patients was nearly twice as high as that of ESRD-negative patients.

- ESRD-positive patients had a significantly higher risk of death within 4 years after a first-ever mechanical ventilation, whether or not they were admitted to the intensive care unit.

- After 4 years of follow-up, however, there was no significant difference in mortality rates between ESRD-positive and ESRD-negative patients.

- In addition to ESRD, older age, being male, being admitted by a medical department, multiple organ failure, and a history of comorbid diabetes mellitus, liver cirrhosis, cancer, stroke, and congestive heart failure are associated with a higher mortality rate after a first-ever mechanical ventilation.

\section{Additional files}

Additional file 1: ICD-9CM codes for comorbidities. (DOCX $13 \mathrm{~kb}$ ) Additional file 2: The 30-day, 6-month, and 1-, 2-, 5-, and 10-year survival rate differences in the ESRD ${ }^{\text {Pos }}$ and ESRD ${ }^{\text {Neg }}$ groups from the beginning. (DOCX $17 \mathrm{~kb}$ )
Additional file 3: Crude and adjusted hazard ratios (HR) of death in ESRD ${ }^{\text {Pos }}$ patients treated with ventilation (derived from Cox proportional hazard regression models). (DOCX $16 \mathrm{~kb}$ )

\section{Abbreviations}

1-MV: first-ever mechanical ventilation; ARF: acute respiratory failure: CAD: coronary artery disease; CHF: congestive heart failure; Cl: confidence interval; CKD: chronic kidney disease; COPD: chronic obstructive pulmonary disease; DM: diabetes mellitus; ESRD: end-stage renal disease; ESRD ${ }^{\text {Neg; controls }}$ without ESRD; ESRD Pos: patients with ESRD; HR: hazard ratio; HTN: hypertension; ICD-9-CM: International Classification of Diseases, Ninth Revision, Clinical

Modification; ICU: intensive care unit; IR: incidence rate; IRB: Institutional Review Board; IRR: incidence rate ratio; LHID2000: Longitudinal Health Insurance Database 2000; MV: mechanical ventilation; NHIRD: National Health Insurance Research Database; NHRI: National Health Research Institute.

\section{Competing interests}

The authors declare that they have no competing interests.

\section{Authors' contributions}

CMC contributed to the study design, helped collect data, and helped draft the manuscript. SFW contributed to the study design, helped do the statistical analysis, and revised the manuscript. CCL and KCC contributed to the study design and revised the manuscript. HNS contributed to the study design, helped collect data, helped do the statistical analysis, and revised the manuscript. WLL helped collect data and revise the manuscript. All authors read and approved the final manuscript.

\section{Acknowledgments}

We thank the staff of the Taiwan Bureau of National Health Insurance, Bureau of Health Promotion, and Department of Health. This research was funded by grant number CMFHR10446 from Chi-Mei Medical Center.

\section{Author details}

'Department of Recreation and Health-Care Management, Chia Nan University of Pharmacy and Science, No.60, Sec. 1, Erren Road., Rende District, Tainan 71710, Taiwan. ${ }^{2}$ Department of Hospital and Health Care Administration, Chia Nan University of Pharmacy and Science, Tainan, Taiwan. ${ }^{3}$ Southern Taiwan University of Science and Technology, No. 1, Nan-Tai Street, Yungkang District, Tainan 710, Taiwan. ${ }^{4}$ Department of Intensive Care Medicine, Chi Mei Medical Center, 901 Chung Hwa Road, Yungkang District, Tainan 710, Taiwan. ${ }^{5}$ Department of Internal Medicine, Chi Mei Medical Center, 901 Chung Hwa Road, Yungkang District, Tainan 710, Taiwan. ${ }^{6}$ Department of Healthcare Administration and Medical Informatics, Kaohsiung Medical University, Kaohsiung, Taiwan. ${ }^{7}$ Department of Intensive Care Medicine, Chi Mei Medical Center, Liouying District, 201, Taikang, Taikang Village, Liouying District, Tainan 736, Taiwan. ${ }^{8}$ Department of Safety, Health and Environment, Chung Hwa University of Medical Technology, 89, Wenhua 1st Street, Rende District, Tainan 717, Taiwan. ${ }^{9}$ Department of Public Health, College of Medicine, National Cheng Kung University, 1, University Road, Tainan 701, Taiwan.

Received: 15 May 2015 Accepted: 18 September 2015

Published online: 01 October 2015

\section{References}

1. Yang WC, Hwang SJ. Taiwan Society of N. Incidence, prevalence and mortality trends of dialysis end-stage renal disease in Taiwan from 1990 to 2001: the impact of national health insurance. Nephrol Dial Transplant. 2008;23:3977-82.

2. U.S. Renal Data System. USRDS 2008 Annual Data Report: atlas of end-stage renal disease in the United States. Bethesda, MD: National Institutes of Health National Institute of Diabetes and Digestive and Kidney Diseases; 2008.

3. The Report of National Health Insurance, 2007 [in Chinese]. Bureau of National Health Insurance (BNHI), Department of Health, Republic of China (Taiwan); 2007. http://www.nhi.gov.tw/Resource/webdata/ Attach_8965_2_\%E9\%87\%8D\%E5\%A4\%A7\%E5\%82\%B7\%E7\%97\%85\%E9\% A0\%98\%E8\%AD\%89\%E6\%95\%B8\%E8\%A1\%A818-\%E9\%99\%84\%E4\%BB\% B68.pdf. Asscessed in 14 July 2015. 
4. The Report of National Health Insurance, 2011 [in Chinese]. Bureau of National Health Insurance (BNHI), Department of Health, Republic of China (Taiwan); 2011. http://www.nhi.gov.tw/webdata/webdata.aspx?menu=17\& menu_id=661\&WD_ID=685\&webdata_id=3627. Accessed 14 July 2015.

5. Collins AJ, Foley RN, Chavers B, Gilbertson D, Herzog C, Ishani A, et al. US Renal Data System 2013 Annual Data Report. Am J Kidney Dis. 2014;63:A7.

6. Chan M, Ostermann M. Outcomes of chronic hemodialysis patients in the intensive care unit. Crit Care Res Pract. 2013;2013:715807.

7. Strijack B, Mojica J, Sood M, Komenda P, Bueti J, Reslerova M, et al. Outcomes of chronic dialysis patients admitted to the intensive care unit. J Am Soc Nephrol. 2009;20:2441-7.

8. Uchino S, Morimatsu H, Bellomo R, Silvester W, Cole L. End-stage renal failure patients requiring renal replacement therapy in the intensive care unit: incidence, clinical features, and outcome. Blood Purif. 2003:21:170-5.

9. Hutchison CA, Crowe AV, Stevens PE, Harrison DA, Lipkin GW. Case mix, outcome and activity for patients admitted to intensive care units requiring chronic renal dialysis: a secondary analysis of the ICNARC Case Mix Programme Database. Crit Care. 2007;11:R50.

10. Apel M, Maia VP, Zeidan M, Schinkoethe C, Wolf G, Reinhart K, et al. End-stage renal disease and outcome in a surgical intensive care unit. Crit Care. 2013;17:R298.

11. Arulkumaran N, Annear NM, Singer M. Patients with end-stage renal disease admitted to the intensive care unit: systematic review. Br J Anaesth. 2013;110:13-20.

12. Bell M, Granath F, Schon S, Lofberg E, SWING, Ekbom A, et al. End-stage renal disease patients on renal replacement therapy in the intensive care unit: short- and long-term outcome. Crit Care Med. 2008;36:2773-8.

13. Bagshaw SM, Mortis G, Doig CJ, Godinez-Luna T, Fick GH, Laupland KB. One-year mortality in critically ill patients by severity of kidney dysfunction: a population-based assessment. Am J Kidney Dis. 2006;48:402-9.

14. Clermont G, Acker CG, Angus DC, Sirio CA, Pinsky MR, Johnson JP. Renal failure in the ICU: comparison of the impact of acute renal failure and end-stage renal disease on ICU outcomes. Kidney Int. 2002;62:986-96.

15. Manhes G, Heng AE, Aublet-Cuvelier B, Gazuy N, Deteix P, Souweine B. Clinical features and outcome of chronic dialysis patients admitted to an intensive care unit. Nephrol Dial Transplant. 2005;20:1127-33.

16. Lebiedz P, Knickel L, Engelbertz C, Luders F, Gebauer K, Berdel WE, et al. Impact of preexisting chronic kidney disease on acute and long-term outcome of critically ill patients on a medical intensive care unit. J Nephrol. 2014:27:73-80

17. Esteban A, Frutos-Vivar F, Muriel A, Ferguson ND, Penuelas O, Abraira V, et al. Evolution of mortality over time in patients receiving mechanical ventilation. Am J Respir Crit Care Med. 2013;188:220-30.

18. Chen SC, Shu KH, Chen CH, Wu MY, Yu TM, Chuang YW, et al. Outcome study of patients on maintenance hemodialysis complicated with acute respiratory failure: 1-year data from a medical center in central Taiwan. Acta Nephrol. 2010;24:33-41.

19. Juneja D, Prabhu MV, Gopal PB, Mohan S, Sridhar G, Nayak KS. Outcome of patients with end stage renal disease admitted to an intensive care unit in India. Ren Fail. 2010;32:69-73.

20. Leroy G, Devos P, Lambiotte F, Thevenin D, Leroy O. One-year mortality in patients requiring prolonged mechanical ventilation: multicenter evaluation of the ProVent score. Crit Care. 2014;18:R155.

21. Cely CM, Rojas JT, Maldonado DA, Schein RM, Quartin AA. Use of intensive care, mechanical ventilation, both, or neither by patients with acute lung injury. Crit Care Med. 2010;38:1126-34.

22. Esquinas AM, Dikmen Y. Mechanical ventilation outside intensive care unit. A growing demand in a vulnerable population. Are there possible solutions? J Crit Care. 2013;28:876-7.

23. National Health Insurance Administration http://www.nhi.gov.tw/English/ Index.aspx?menu=13\&menu_id=486\&WD_ID=486. Accessed in 14 July 2015.

24. Center for Biomedical Resources of National Health Research Institutes http://nhird.nhri.org.tw/en/Data_Subsets.html. Dec, 2014.

25. Shen HN, Lu CL, Yang HH. Epidemiologic trend of severe sepsis in Taiwan from 1997 through 2006. Chest. 2010;138:298-304.

26. Go AS, Chertow GM, Fan D, McCulloch CE, Hsu CY. Chronic kidney disease and the risks of death, cardiovascular events, and hospitalization. N Engl J Med. 2004;351:1296-305.

27. Sood MM, Miller L, Komenda P, Reslerova M, Bueti J, Santhianathan C, et al. Long-term outcomes of end-stage renal disease patients admitted to the ICU. Nephrol Dial Transplant. 2011;26:2965-70.
28. Liao JC, Ho CH, Liang FW, Wang JJ, Lin KC, Chio CC, et al. One-year mortality associations in hemodialysis patients after traumatic brain injury-an eight-year population-based study. PLoS One. 2014:9:e93956.

29. Chapman RJ, Templeton M, Ashworth S, Broomhead R, McLean A, Brett SJ. Long-term survival of chronic dialysis patients following survival from an episode of multiple-organ failure. Crit Care. 2009;13:R65.

30. Azevedo LC, Park M, Salluh II, Rea-Neto A, Souza-Dantas VC, Varaschin P, et al. Clinical outcomes of patients requiring ventilatory support in Brazilian intensive care units: a multicenter, prospective, cohort study. Crit Care. 2013;17:R63.

31. Esteban A, Anzueto A, Frutos F, Alia I, Brochard L, Stewart TE, et al. Characteristics and outcomes in adult patients receiving mechanical ventilation: a 28-day international study. JAMA. 2002;287:345-55.

32. Franca SA, Toufen CJ, Hovnanian AL, Albuquerque AL, Borges ER, Pizzo VR, et al. The epidemiology of acute respiratory failure in hospitalized patients: a Brazilian prospective cohort study. J Crit Care. 2011;26:330. e1-8.

33. Carson SS, Kahn JM, Hough CL, Seeley EJ, White DB, Douglas IS, et al. A multicenter mortality prediction model for patients receiving prolonged mechanical ventilation. Crit Care Med. 2012;40:1171-6.

34. Behrendt CE. Acute respiratory failure in the United States: incidence and 31-day survival. Chest. 2000;118:1100-5.

35. Kollef MH, O'Brien JD, Silver P. The impact of gender on outcome from mechanical ventilation. Chest. 1997;111:434-41.

36. Mahmood K, Eldeirawi K, Wahidi MM. Association of gender with outcomes in critically ill patients. Crit Care. 2012;16:R92.

37. Chen CJ, Shi HY, Lee KT, Huang TY. In-hospital mortality prediction in patients receiving mechanical ventilation in Taiwan. Am J Crit Care. 2013;22:506-13.

38. Manzano F, Perez-Perez AM, Martinez-Ruiz S, Garrido-Colmenero C, Roldan D, Jimenez-Quintana Mdel M, et al. Hospital-acquired pressure ulcers and risk of hospital mortality in intensive care patients on mechanical ventilation. J Eval Clin Pract. 2014;20:362-8.

39. Jeong BH, Suh GY, An JY, Park MS, Lee JH, Lee MG, et al. Clinical demographics and outcomes in mechanically ventilated patients in Korean intensive care units. J Korean Med Sci. 2014;29:864-70.

40. Golestanian E, Liou Jl, Smith MA. Long-term survival in older critically ill patients with acute ischemic stroke. Crit Care Med. 2009;37:3107-13.

41. Levesque E, Saliba F, Ichai P, Samuel D. Outcome of patients with cirrhosis requiring mechanical ventilation in ICU. J Hepatol. 2014;60:570-8.

\section{Submit your next manuscript to BioMed Central and take full advantage of:}

- Convenient online submission

- Thorough peer review

- No space constraints or color figure charges

- Immediate publication on acceptance

- Inclusion in PubMed, CAS, Scopus and Google Scholar

- Research which is freely available for redistribution 